\title{
Empowerment across Cultures: How National Culture Affects Structural and Psychological Empowerment and Employee Engagement
}

\author{
Miaoyun (Maria) Zheng \\ Open University of Hong Kong \\ Vane-Ing Tian \\ Open University of Hong Kong
}

The importance of empowerment has grown in the past decades. Empowerment frees up management's time from minor decision and can focus on broader strategies and the long-term objectives of the company. This paper aims to contribute empirically to the research of empowerment across cultures in manufacturing environment, focusing on how national culture dimensions affect structural and psychological empowerment and employee engagement. The data base on a practitioner's model on sustainable engagement, in which both constructs of empowerment and sustainable engagement were surveyed and measured in a global manufacturing company for its group companies across more than 20 national cultures.

Keywords: Structural Empowerment, Psychological Empowerment, Employee Engagement, Culture Dimensions

\section{INTRODUCTION}

The importance of empowerment is well recognized and has grown in the past decades. Smith stated that the importance of empowerment grows and "goes hand in hand with social changes, with what technology enables us to do and with the demands of the competitive environment." (Smith, 1996, p.12). Baird et al. suggest that organizations' ability to respond quickly to changes in the environment is becoming more important and empowering employees can contribute to that objective as it reduces time caused by the unnecessary communication up and down the organization (Baird et al., 2010). They argue that empowerment frees up management's time from minor decision, and can focus on broader strategies and the long-term objectives of the company, which is important for the sustainable business growth (Baird et al., 2010).

Some studies have shown that empowering leadership behaviors, characterized by the redistributing decision-making power to those who usually do not have it and gives employees more power to make their own decisions, contribute statistically significantly to employee engagement and low turnover intention (e.g. Albrecht and Andreetta, 2011), and organizational performance (e.g. Baird et al., 2018). Mathieu et al. argue that empowering employees should enable organizations to become more flexible and responsive (Mathieu et al., 2016). Therefore, empowerment can lead to improvements in both 
individual and organizational performance. A number of studies on psychological empowerment have demonstrated its desirable outcomes for organizations, for example a direct relationship between psychological empowerment and managerial effectiveness and innovative behaviors (Spreitzer, 1995), or its mediating effect on structural empowerment and individual performance and employee job satisfaction (eg Seibert et al., 2004). Some researches show that psychological empowerment has a direct influence on employee engagement (eg. Albrecht and Andreetta, 2010).

Despite the importance and many benefits of employee empowerment, not enough researches have been made about contextual factors associated with empowerment, such as cultural factors, an employee's position in an organization, and so on as suggested (Maynard et al., 2012). Hui et al. empirically demonstrated that the effect of empowerment on employee satisfaction is less in high (versus low) power distance societies (Hui et al., 2004). They argue that empowerment is less compatible with the cultural values of societies high in power distance. Over the years, Fock et al. find that empowerment remains an effective employee management strategy, but to varying extents across cultures subject to the type of empowerment in question, as the meaning and conceptualization of empowerment varies with the operationalized constructs (Fock et al., 2013).

A lot of researches have focused on studying empowerment in service organizations (e.g. Hui et al., 2004), as frontline employees in service organizations are likely to be required to provide prompt and flexible services for their customers, thus it is important to implement empowerment in the service industry. Hui et al argue that factory workers are performing simple and routine jobs, discretion and autonomy as characteristics of empowerment may actually create unnecessary confusion and uncertainty for the employee (Hui et al., 2004). They argue that discretion and autonomy given to factory workers might produce no, or even negative effects on job behavior. On the other hand, the research by Hirzel \& Leyer found that when there is a significant increase in empowerment for employees' continuous improvement over time, it would have a positive but time-lagged relationship with the level of continuous improvement implementation (Hirzel \& Leyer, 2017). Continuous improvement, as a structured approach to quality and process improvement, including TQM, lean manufacturing and six Sigma, is a key concept applied in manufacturing companies, as Mclean \& Antony point out (Mclean \& Antony, 2017).

This paper aims to contribute empirically to the research of empowerment across cultures in manufacturing environment, focusing on how national culture dimensions affect structural and psychological empowerment and employee engagement. The data base on a practitioner's model on sustainable engagement, in which both constructs of empowerment and sustainable engagement were surveyed and measured in a global manufacturing company for its group companies across more than 20 national cultures.

This paper is divided into six sections. The Introduction section briefly discusses the existing literature on empowerment, engagement and national culture dimensions and the hypotheses are described. In the second section, the research methodology employed is outlined. In the third section, the data analysis and results are given. In the fourth and fifth sections, the discussion and conclusions are explained, and the limitations of this study are presented. The references are listed in the last section.

Liden and Arad noted that literature on empowerment, include both macro perspective (focusing on organizational structures and policies) and a micro perspective (focusing on empowerment as intrinsic motivation) (Liden and Arad, 1996). These are the two distinct constructs of empowerment, commonly known as psychological empowerment (eg. Conger et al., 1988; Thomas., 1990; Fock et al., 2011; Spreitzer, 1995) and structural empowerment (eg. Kanter, 1988).

\section{Structural Empowerment}

Kanter argues that employee attitudes and behaviors are influenced more by social structures in the workplace (e.g., access to information and resources, work unit climate), rather than by individual personality traits (Kanter, 1988). He identified four avenues of power in an organization as the sources of structural empowerment, namely "access to information", "access to resources necessary to do the job", "having the opportunity to learn and grow", and "receiving support". 


\section{Psychological Empowerment}

Conger et al. (1988) argue that empowering leadership behaviors demonstrated in the structural empowerment are only one set of conditions and that leaders may empower employees but employees will not necessarily like to be empowered (Conger et al., 1988). In the same research direction as Conger et al., Thomas and Velthouse advocate that psychological empowerment can distinguish between situational attributes (e.g., empowering leadership management practice) and job incumbent cognitions of those attributes (Thomas and Velthouse 1990). They define psychological empowerment as increased intrinsic task motivation manifested in a set of four cognitions reflecting an individual's orientation to his or her work role: meaning, competence, self-determination, and impact (Thomas and Velthouse, 1990). Spreitzer further developed and validated a multidimensional measure to assess the psychological empowerment in the workplace (Spreitzer, 1995).

Smith, as an practitioner consultant, advocates that empowerment makes it possible for companies to get closer to the customer, improve service delivery, continuously innovate, increase productivity and gain the competitive advantage (Smith, 1996). Empowerment by Smith refers to management practices of empowering people by "encouraging them to become more involved in the decisions and activities that affect their jobs. It means providing them with the opportunity to show that they can come up with good ideas and that they have the skills to put these ideas into practice." (Smith, 1996, p9).

This research uses empowerment behaviors surveyed in a practitioner's model based on Kanter's four avenues of power of structural empowerment and the four cognitions of psychological empowerment and their impact on employee engagement.

\section{Employee Engagement}

Although there is no widely accepted definition of employee engagement, Welch suggests that the most frequently referenced definitions of employee engagement are the ones by Kahn (Kahn, 1990) and Schaufeli \& Bakker (Schaufeli \& Bakker, 2004), whose studies both focus on the cognitive, emotional and physical manifestations of engagement (Welch, 2011).

Comparing with academic researches, from the Human Resource Development (HRD) practitioner perspective, Shuck \& Wollard highlight the need for identifying the organizational factors that best promote positive employee attitudes, behaviors and positive organizational performance (Shuck \& Wollard, 2010). They define employee engagement in the HRD literature as "an individual employee's cognitive, emotional, and behavioral state directed toward desired organizational outcomes" (Shuck \& Wollard, 2010, p103).

Willis Towers Watson (WLTW, 2016) translates the employee states into behaviors that are displayed in the organizational context. They argue that organizations should go beyond the traditional engagement, a state that describes an employee's attachment to the company and willingness to give discretionary effort. They believe the relationship between traditional engagement and performance typically focused on the organizations in a steady state. In reality, organizations face changes in their business operations, which can cause employees to be ineffective despite they are traditionally "engaged". They advise employers to provide the support employees need to do their work efficiently and effectively, which is what WLTW calls "enabled" or empowered. Employers should also create a healthful work environment - one that supports employees' physical, social and emotional well-being, which they refer to as "energized". WLTW argues that highly engaged employees would produce better business outcomes than their less engaged coworkers. However, engagement alone does not guarantee top performance. Companies should be able to realize greater value by not only engaging employees, but also enabling and energizing their efforts. This is what they call sustainable engagement, as depicted in the graph 1 below. 


\section{FIGURE 1 \\ MODEL OF SUSTAINABLE ENGAGEMENT (WLTW: 2016)}

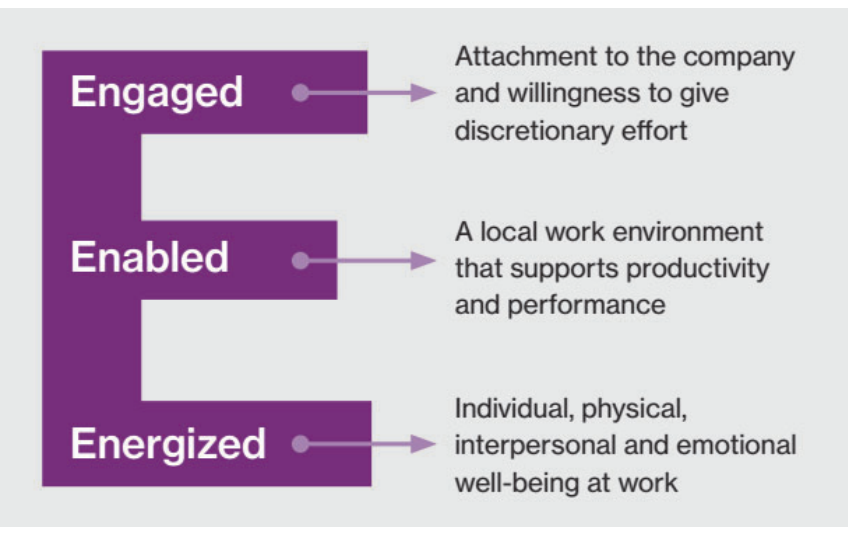

\section{Relationship between Empowerment and Engagement}

Mone et al. suggest the state of engaged employees as "those who feel involved, committed, passionate, and empowered, and demonstrate those feelings in work behavior" (Mone et al., 2011). Prathiba argues that employee empowerment and employee engagement collectively influence on organizational commitment positively and organizational commitment is the force that binds an employee's course of action to achieve targets (Prathiba, 2016). Albrecht and Andreetta suggest that beyond the direct effect of psychological empowerment on employee engagement, empowering leadership have indirect effects on engagement (Albrecht and Andreetta, 2011). The following hypotheses regarding perceived structural empowerment, perceived psychological empowerment and perceived employee engagement will be tested:

\section{H1: Perceived structural empowerment is positively related to perceived psychological empowerment.}

H2: Perceived structural empowerment is positively related to perceived employee engagement, however the positive impact of structural empowerment on employee engagement is mediated through psychological empowerment.

\section{H3: Perceived psychological empowerment is positively related to perceived employee engagement.}

\section{Hofstede's Culture Dimensions}

Some authors (eg. Eylon and Au, 1999; Hui et al., 2004; Hoffman \& Shipper, 2012; Fock et al., 2011; Zhang \& Zhou, 2014 and so on) have studied the empowerment in a cross culture context, with reference to Hofstede's cultural dimensions, in particular power distance, and some referred to uncertainty avoidance and individualism vs collectivism (Hofstede, 1980).

Power distance refers to the degree to which members of society accept an uneven distribution of power (Hofstede, 1980). Eylon \& Au were the first ones who studied empowerment across cultures (Eylon \& Au, 1999). They suggest that high power distance cultures are more accustomed to paternal and centralized leadership, which means they accept power is distributed unequally, while those from low power distance cultures prefer delegation and they accept relatively equal power distribution. Their studies revealed that both the high and low power distance groups perceived the positive relationship between empowerment treatments and their levels of job satisfaction, however their work performances are different. The low power distance group performed quite similarly no matter they were empowered or not, while the participants in high power distance group did significantly less well in empowered condition, as they are more used to receiving decisions and task guidelines from above. Hui et al. empirically demonstrated that the effect of discretion empowerment on employee job satisfaction 
becomes less pronounced in high (versus low) power distance societies (Hui et al, 2004). Their study revealed that employees from a high power distance culture expect their supervisors to behave autocratically. Employees may even feel uncomfortable if supervisors consult them. A similar group of researchers, Fock et al. point out that the three studies of Hui et al. (Hui et al, 2004) operationalized empowerment largely as discretion empowerment (Fock et al., 2013). Fock et al. examine the moderation effects of power distance across three types of empowerment: discretion empowerment, psychological empowerment, and leadership empowerment (Fock et al., 2013). They conclude that the effect of discretion empowerment on employee satisfaction is affected by power distance based on the findings obtained from both national-level and individual-level analyses. On the other hand, current research argues that people from a higher level of power distance culture have a lower demand for authority, which may lead to a higher level of satisfaction, meaning that they may feel psychologically they are sufficiently empowered. Based on the analysis of the surveyed items in WLTW's model, the researcher will test the following hypotheses regarding power distance in relations to perceived structural empowerment, perceived psychological empowerment and perceived employee engagement

H4: There is a positive relationship between power distance and a) perceived structural empowerment, $b$ ) perceived psychological empowerment and c) perceived employee engagement.

Based on previous researches, Hoffman \& Shipper conclude that cross-culturally participative leader behaviors are positively associated with job satisfaction and decision commitment in cultures with low power distance and low uncertainty avoidance (Hoffman \& Shipper, 2012). Uncertainty avoidance was defined as "the extent to which a society feels threatened by uncertain and ambiguous situations and tries to avoid these situations by providing greater career stability, establishing more formal rules, not tolerating deviant ideas and behaviors, and believing in absolute truths and the attainment of expertise", (Hofstede, 1980, p45). Zhang \& Zhou suggests that empowering leadership can increase creativity in employees with high uncertainty avoidance tendency (Zhang \& Zhou, 2014). Their research revealed that empowering leadership was most effective at promoting creativity for these individuals with high levels of uncertainty avoidance when they trusted their supervisors. However, empowering leadership was shown not to be very effective at promoting creativity for other combinations of uncertainty avoidance and trust, e.g., when employees had high levels of uncertainty avoidance and low trust, or when they had low levels of uncertainty avoidance and high trust. It was surprising that the combination of lower level of uncertainty avoidance and high trust doesn't effectively promoting creativity, as Hofstede et al. highlight one of the key characteristics for lower level of uncertainty avoidance is better at invention which requires creativity (Hofstede et al., 2010). Baird et al. suggest that organizations should respond rapidly to changes in the business environment. Empowering employees can contribute to that objective as it eliminates extensive communication up and down the organizational hierarchy (Baird et al., 2010). Coming along with a rapid response to change when employees are empowered, it is uncertainty. Based on the analysis of the surveyed items in WLTW's model, the researcher will test the following hypotheses regarding uncertainty avoidance in relations to perceived structural empowerment, perceived psychological empowerment and perceived employee engagement

H5: There is a negative relationship between uncertainty avoidance and a) perceived structural empowerment, b) perceived psychological empowerment and c) perceived employee engagement.

For individualism and collectivism in the workplace, Hofstede et al. stated, "Employed persons in an individualist culture are expected to act according to their own interests, and work should be organized in such a way that this self-interest and the employer's interest coincide. ... In a collectivist culture, the employees will act according to the interest of the in-group, which may not always coincide with his or her interest." (Hofstede et al., 2010: 119). Chen et al. collected cross-cultural laboratory and field studies data with samples including leaders, employees, and students from the United States and the People's Republic of China, to examine how empowering leadership and relationship conflict, combine to 
influence individual members' motivational states of psychological empowerment and affective commitment (Chen et al., 2011). Even though they found the positive relationship between collectivism and psychological empowerment, they also paradoxically found that Americans, high in individualism and low in collectivism, reported higher levels of psychological empowerment than their Chinese counterparts did. They argue that the culture differences at the societal level may relate to psychological empowerment differently at the individual level. The researcher found the opposite phenomenon in the current study, in which Chinese participants showed higher perceived structural and psychological empowerment than US participants. Chen et al. suggested that it is possible that individualism/collectivism does not affect the perceived level of empowering leadership in a statistically significant way (Chen et al., 2011). Based on the analysis of the surveyed items in WLTW's model, the researcher will test the following hypotheses regarding individualism in relations to perceived structural empowerment, perceived psychological empowerment and perceived employee engagement

H6: There is a negative relationship between individualism and a) perceived structural empowerment, b) perceived psychological empowerment and c) perceived employee engagement.

Most of the available researches about cross-cultural influences on empowerment only compare two or a few countries due to the limitation of data collection. The current research aims to study the correlations between three culture dimensions and empowerment and engagement. The second objective of this study is to analyze the practitioner's survey findings based on the research conceptualization and constructs of empowerment from a collective level, i.e. national culture level. National culture level study focuses on the patterns of thinking, feeling and acting that are specific to a group or category, rather than from individual level, which focuses on unique personal set of mental programs.

\section{Hypothetical Framework and Model}

The overall hypothetical framework and model is as depicted in Graph 2 below: 
FIGURE 2

\section{HYPOTHETICAL FRAMEWORK AND MODEL}

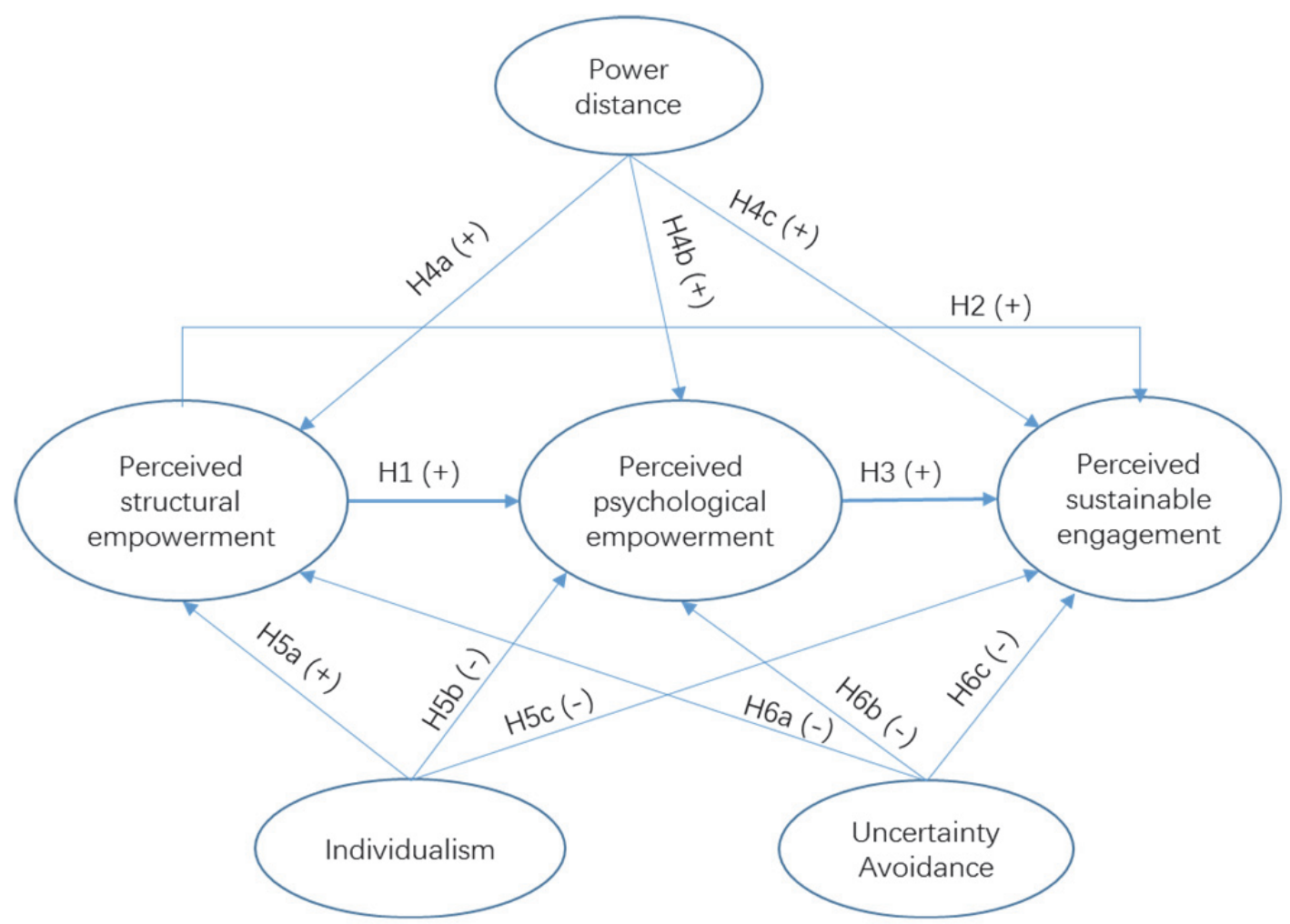

\section{METHODOLOGY}

Schiele \& Krummaker call for making management research of more interest to practitioners by bringing more relevance to management practice through closing the gap between knowledge production and knowledge transfer (Schiele \& Krummaker, 2011). Successful production of relevant knowledge depends on how well researchers can translate theoretical knowledge into the language of practice (Shapiro et al., 2007). The researcher, as an HRD practitioner, will strive to contribute to the knowledge development with practice-grounded work. This study aims to analyze the employee engagement feedback collected through WLTW's online survey tool by matching the survey elements with structural and psychological empowerment elements, in the hope to contribute to empirical study on the relationship between the different empowerment constructs and employee engagement.

The data was collected in 2017 in a global manufacturing company with its group companies located in 25 countries. Perceived structural empowerment is measured by nine items in four dimensions, perceived psychological empowerment is measured by eight items in four dimensions. Employee engagement is measured by 5 items, which is defined as sustainable engagement by WLTW. Participants' demographics are shown in Graph $3 \& 4$ as follows: 


\section{FIGURE 3}

\section{EMPLOYEE SURVEY PARTICIPATING COUNTRIES AND THE NUMBER OF PARTICIPANTS}

Country Level
Japan
Belgium
Srance
Italy
Retherlands
Russia
Slovakia
Turkey
Germany

\begin{tabular}{|c|c|c|}
\hline 7,989 & India ............ & 827 \\
\hline 35 & Indonesia .......... & 1,251 \\
\hline 1,248 & Malaysia ................ & 172 \\
\hline 248 & New Zealand .... & 10 \\
\hline 239 & India_Finance & 380 \\
\hline 56 & 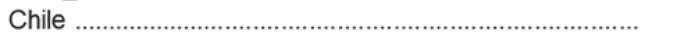 & 1,140 \\
\hline 106 & 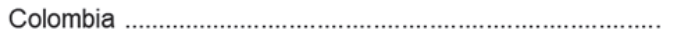 & 330 \\
\hline 411 & Costa Rica .............................. & 194 \\
\hline 129 & Ecuador .................................. & 555 \\
\hline 572 & Mexico ................... & 20 \\
\hline 284 & Peru............... & 569 \\
\hline 1,866 & 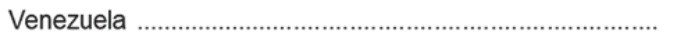 & 373 \\
\hline 748 & United States & 1,224 \\
\hline
\end{tabular}

FIGURE 4

EMPLOYEE SURVEY PARTICIPANTS DEMOGRAPHICS

\begin{tabular}{|c|c|c|c|}
\hline 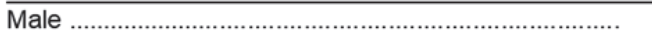 & 18,242 & Female & 2,334 \\
\hline \multicolumn{4}{|l|}{ Age } \\
\hline 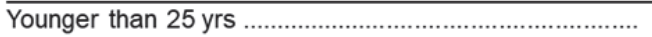 & 1,690 & 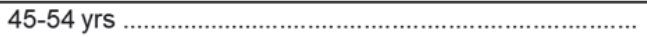 & 2,925 \\
\hline 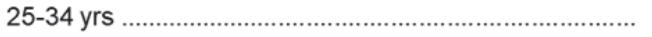 & 8,533 & 55 yrs and older & 1,048 \\
\hline 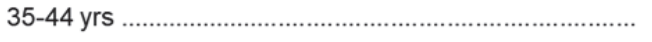 & 6,416 & & \\
\hline \multicolumn{4}{|l|}{ Tenure } \\
\hline < 1 year & 2,216 & 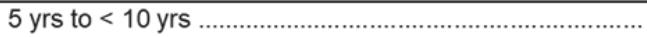 & 6,375 \\
\hline 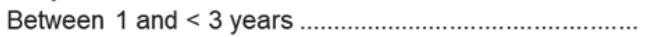 & 2,436 & 10 yrs to $<20$ yrs & 5,058 \\
\hline 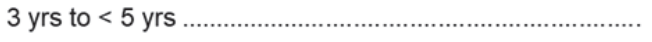 & 2,478 & 20 yrs and above & 2,031 \\
\hline \multicolumn{4}{|l|}{ Position in the Organization } \\
\hline 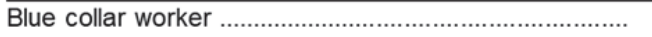 & 14,727 & Manager .......................... & 1,442 \\
\hline White collar worker. & 4,449 & & \\
\hline
\end{tabular}

Considering time and cost perspective, the researcher make use of secondary data of Hofstede's culture dimensions. Alvarez et al. also suggests that using secondary data can be more efficient in training students in research methods (Alvarez et al., 2012). The country level data of power distance, individualism and uncertainty avoidance are obtained from Hofstede Insights online database (https://www.hofstede-insights.com/).

Quantitative and qualitative analysis and statistical techniques like correlation and multiple regression analysis are employed to measure the significance and strength of relationship between survey items with the structural and psychological empowerment and its dimensions and employee engagement.

\section{RESULTS}

We test for reliability of the perceived structural empowerment and perceived psychological empowerment. The reliability of perceived structural empowerment and psychological empowerment are 0.945 and 0.942 respectively, both are larger than 0.7. Therefore, we test our research hypotheses.

To test the research hypotheses, we run correlation test and the result is show in Figure 5. 


\section{FIGURE 5 \\ CORRELATION BETWEEN PERCEIVED STRUCTURAL EMPOWERMENT, PERCEIVED PSYCHOLOGICAL EMPOWERMENT, EMPLOYEE ENGAGEMENT, AND HOFSTEDE CULTURAL DIMENSIONS}

\begin{tabular}{|c|c|c|c|c|c|c|c|}
\hline & & $\begin{array}{c}\text { Structural } \\
\text { Empowerment }\end{array}$ & $\begin{array}{l}\text { Psychological } \\
\text { Empowerment }\end{array}$ & $\begin{array}{l}\text { Sustainable } \\
\text { Engagement }\end{array}$ & $\begin{array}{c}\text { Power } \\
\text { Distance }\end{array}$ & Individualism & $\begin{array}{l}\text { Uncertainty } \\
\text { Avoidance }\end{array}$ \\
\hline \multirow[t]{3}{*}{$\begin{array}{l}\text { Structural } \\
\text { Empowerment }\end{array}$} & $\begin{array}{l}\text { Pearson } \\
\text { Correlation }\end{array}$ & 1 & $.918^{\star *}$ & $.825^{\star *}$ & $.602^{* \star}$ & $-.589^{\star *}$ & -.174 \\
\hline & Sig. (2-tailed) & & .000 & .000 & .001 & .002 & .405 \\
\hline & $N$ & 25 & 25 & 25 & 25 & 25 & 25 \\
\hline \multirow[t]{3}{*}{$\begin{array}{l}\text { Psychological } \\
\text { Empowerment }\end{array}$} & $\begin{array}{l}\text { Pearson } \\
\text { Correlation }\end{array}$ & & 1 & $.921^{\star \star}$ & $.431^{*}$ & & -.104 \\
\hline & Sig. (2-tailed) & .000 & & .000 & .032 & .002 & .620 \\
\hline & $\mathrm{N}$ & 25 & 25 & 25 & 25 & 25 & 25 \\
\hline \multirow[t]{3}{*}{$\begin{array}{l}\text { Sustainable } \\
\text { Engagement }\end{array}$} & $\begin{array}{l}\text { Pearson } \\
\text { Correlation }\end{array}$ & $.825^{\star *}$ & $.921^{\star \star}$ & 1 & .268 & $-.465^{*}$ & -.093 \\
\hline & Sig. (2-tailed) & .000 & .000 & & .196 & .019 & .659 \\
\hline & $\mathrm{N}$ & 25 & 25 & 25 & 25 & 25 & 25 \\
\hline \multirow[t]{3}{*}{ Power Distance } & $\begin{array}{l}\text { Pearson } \\
\text { Correlation }\end{array}$ & $.602^{* *}$ & $.431^{\star}$ & .268 & 1 & $-.506^{* *}$ & -.031 \\
\hline & Sig. (2-tailed) & .001 & .032 & .196 & & .010 & .884 \\
\hline & $\mathrm{N}$ & 25 & 25 & 25 & 25 & 25 & 25 \\
\hline \multirow[t]{3}{*}{ Individualism } & $\begin{array}{l}\text { Pearson } \\
\text { Correlation }\end{array}$ & $-.589^{\star *}$ & $-.582^{\star \star}$ & $-.465^{*}$ & $-.506^{* *}$ & 1 & -.233 \\
\hline & Sig. (2-tailed) & .002 & .002 & .019 & .010 & & .262 \\
\hline & $\mathrm{N}$ & 25 & 25 & 25 & 25 & 25 & 25 \\
\hline \multirow[t]{3}{*}{$\begin{array}{l}\text { Uncertainty } \\
\text { Avoidance }\end{array}$} & $\begin{array}{l}\text { Pearson } \\
\text { Correlation }\end{array}$ & -.174 & -.104 & -.093 & -.031 & -.233 & 1 \\
\hline & Sig. (2-tailed) & .405 & .620 & .659 & .884 & .262 & \\
\hline & $\mathrm{N}$ & 25 & 25 & 25 & 25 & 25 & 25 \\
\hline
\end{tabular}

From Figure 5, there are significant positive correlations between perceived structural empowerment, perceived psychological empowerment, and perceived employee engagement. Therefore, our hypotheses 1 to 3 are supported.

There are significant positive correlations between power distance and perceived structural empowerment, and between power distance and psychological empowerment. Therefore, our hypotheses $4 \mathrm{a}$ and $4 \mathrm{~b}$ are supported. However, there is no significant relationship between power distance and employee engagement and hypothesis $4 \mathrm{c}$ is not supported.

There are significant negative correlations between individualism and perceived structural empowerment, psychological empowerment, and employee engagement. Therefore, our hypotheses 5a, $5 \mathrm{~b}$ and $5 \mathrm{c}$ are supported.

There are no significant correlations between uncertainty avoidance and perceived structural empowerment, psychological empowerment, and employee engagement. Therefore, our hypotheses $6 \mathrm{a}$, $6 \mathrm{~b}$ and $6 \mathrm{c}$ are not supported. Although the direction of correlations is negative.

Regression test is also run to examine the relationship between structural empowerment and Hofstede's cultural dimensions (power distance, individualism and uncertainty avoidance). It shows that individualism have significant negative relationship, power distance have marginally significant positive relationship, and uncertainty avoidance have marginally significant negative relationship, with structural empowerment $(\mathrm{R} 2=0.735)$. See Table 1 . 
TABLE 1

REGRESSION RESULT - STRUCTURAL EMPOWERMENT

Coefficients $^{\mathrm{a}}$

\begin{tabular}{|c|c|c|c|c|c|c|}
\hline \multirow{2}{*}{\multicolumn{2}{|c|}{ Model }} & \multicolumn{2}{|c|}{ Unstandardized Coefficients } & $\begin{array}{l}\text { Standardized } \\
\text { Coefficients }\end{array}$ & \multirow[b]{2}{*}{$\mathrm{T}$} & \multirow[b]{2}{*}{ Sig. } \\
\hline & & $\mathrm{B}$ & Std. Error & Beta & & \\
\hline \multirow[t]{4}{*}{1} & (Constant) & 79.041 & 10.596 & & 7.459 & .000 \\
\hline & Power Distance & .178 & .088 & .354 & 2.030 & .055 \\
\hline & Individualism & -.186 & .070 & -.474 & -2.648 & .015 \\
\hline & Uncertainty Avoidance & -.132 & .074 & -.274 & -1.772 & .091 \\
\hline
\end{tabular}

a. Dependent Variable: Structural Empowerment

For the relationship between psychological empowerment and Hofstede's cultural dimensions (power distance, individualism and uncertainty avoidance). It shows that individualism have significant negative relationship with psychological empowerment $(\mathrm{R} 2=0.413)$. See Table 2 .

\section{TABLE 2}

\section{REGRESSION RESULT - PSYCHOLOGICAL EMPOWERMENT}

\begin{tabular}{|c|c|c|c|c|c|c|}
\hline \multicolumn{7}{|c|}{ Coefficients $^{\mathrm{a}}$} \\
\hline \multirow{2}{*}{\multicolumn{2}{|c|}{ Model }} & \multicolumn{2}{|c|}{ Unstandardized Coefficients } & \multirow{2}{*}{$\begin{array}{c}\text { Standardized } \\
\text { Coefficients } \\
\text { Beta }\end{array}$} & \multirow[b]{2}{*}{$\mathrm{T}$} & \multirow[b]{2}{*}{ Sig. } \\
\hline & & $\mathrm{B}$ & Std. Error & & & \\
\hline 1 & (Constant) & 90.596 & 11.451 & & 7.912 & .000 \\
\hline & Power Distance & .066 & .095 & .137 & .695 & .495 \\
\hline & Individualism & -.213 & .076 & -.566 & -2.797 & .011 \\
\hline & Uncertainty Avoidance & -.107 & .080 & -.232 & -1.328 & .198 \\
\hline
\end{tabular}

a. Dependent Variable: Psychological Empowerment

To test for the relative impact of structural empowerment and psychological empowerment on employee engagement, regression result is shown in Table 3. The positive impact of structural empowerment become insignificant after psychological empowerment is added to the equation, suggesting the impact of structural empowerment on employee engagement is mediated through psychological empowerment.

TABLE 3

REGRESSION RESULT - EMPLOYEE ENGAGEMENT

\begin{tabular}{|c|c|c|c|c|c|}
\hline \multicolumn{6}{|c|}{ Coefficients $^{\mathrm{a}}$} \\
\hline \multirow[b]{2}{*}{ Model } & \multicolumn{2}{|c|}{$\begin{array}{l}\text { Unstandardized } \\
\text { Coefficients }\end{array}$} & \multirow{2}{*}{\begin{tabular}{|c|}
$\begin{array}{c}\text { Standardized } \\
\text { Coefficients }\end{array}$ \\
Beta \\
\end{tabular}} & \multirow[b]{2}{*}{$\mathrm{T}$} & \multirow[b]{2}{*}{ Sig. } \\
\hline & $\mathrm{B}$ & Std. Error & & & \\
\hline $1 \quad$ (Constant) & 3.884 & 6.894 & & .563 & .579 \\
\hline Structural Empowerment & -.134 & .212 & -.132 & -.636 & .532 \\
\hline Psychological Empowerment & 1.108 & .221 & 1.042 & 5.008 & .000 \\
\hline
\end{tabular}

a. Dependent Variable: Employee Engagement 


\section{DISCUSSION}

This current study examined the relationship between Hofstede's culture dimensions of power distance, individualism and uncertainty avoidance and structural and psychological empowerment and employee engagement. The survey results confirmed the hypotheses that there are positive relationship between structural and psychological empowerment and employee engagement, and the psychological empowerment mediates the positive impact of structural empowerment on employee engagement. Managers can increase employee engagement through structural empowerment, but its effectiveness depends on the perceived psychological empowerment. Power distance has positive relationship with structural and psychological empowerment, however the positive relationship with employee engagement is not confirmed. Therefore, employees in culture with high power distance will perceive higher structural and psychological empowerment with the same empowerment leadership practices. However, the employee engagement may not be higher. Individualism has negative relationship with structural and psychological empowerment and employee engagement. Therefore, employees in individualistic culture will perceive lower structural and psychological empowerment with the same empowerment leadership practices. There are no significant correlations between uncertainty avoidance and perceived structural empowerment, psychological empowerment, and employee engagement. It is thus important for practitioners and managers who manage across cultural borders in international business context to be aware that it is crucial to understand how employees with different cultural values perceive empowerment in order to achieve the intended benefits of empowerment on employee engagement.

\section{CONCLUSION}

To the best of our knowledge, this research is a first study about empowerment across multiple national cultures in an international manufacturing company. Previous studies are largely in service industries and only limited number of national cultures are studied. The results show empowerment has positive impacts on employee engagement in an multinational manufacturing companies, which disagree with some of the previous researches (eg. Hui et al, 2004) that casts doubt about the relevance and effectiveness of implementing empowerment in manufacturing companies.

The limitations of this study include the exclusive reliance on self-report data, which may have inflated the relationships among the different dependent variables (Fock et al, 2011). Secondly, the promotion of empowerment as a management practice in this particular international company may have inflated the relationships as well. Another limitation of this study is that only aggregated group data are available for the different dimensions, which limits the probing analysis into individual level. And the validity of the WLTW's sustainable engagement survey items is not available due to the proprietary data protection within practitioner's world. This study is an attempt to contribute empirically to the research of empowerment across cultures in manufacturing environment and the finding of this study proves it is important to implement empowerment in manufacturing companies as well, since it positively affect the employee engagement. But there is a lot to be further studied about empowerment, especially about how empowerment can be deployed effectively. Baird et al. acknowledge that managers face a dilemma in respect to maintaining an adequate control to minimize any potential risks while still giving employees the freedom to be creative, innovative, and flexible (Baird et al., 2018). Thus future research can focus on gaining empirical insights into the relationship between enabling controls and empowerment, contributing to effective empowerment intervention facilitation and deployment. To manage the anxiety and strain empowerment may bring to employees, Jang et al. recommended that work design should takes cultural context into account, as there may be benefits (e.g., lower employee strain) to matching resources afforded to workers by culture or national context (Jang et al., 2016). For the researcher, it is important to continue the study across cultural context, however more focusing on getting the individual level data in the future data collection, so that the researcher can really test on the moderating or mediating effects of empowerment across cultures and its consequences. 


\section{REFERENCES}

Albrecht, S. L., \& Andreetta, M. (2011). The influence of empowering leadership, empowerment and engagement on affective commitment and turnover intentions in community health service workers: Test of a model. Leadership in Health Services, 24(3), 228-237.

Alvarez, J., Canduela, J., \& Raeside, R. (2012). Knowledge creation and the use of secondary data. J Clin Nurs, 21, 2699-2710.

Baird, K., \& Wang, H. (2010). Employee empowerment: extent of adoption and influential factors. Personnel Review, 9(5), 574-599.

Baird, K., Su, S., \& Munir, R. (2018). The relationship between the enabling use of controls, employee empowerment, and performance. Personnel Review, 47(1), 257-274.

Chen, G., Sharma, P. N., Edinger, S. K., Shapiro, D. L., \& Farh, J.-L. (2011). Motivating and demotivating forces in teams: Cross-level influences of empowering leadership and relationship conflict. Journal of Applied Psychology, 96(3), 541-557.

Conger, J.A., \& Kanungo, R. N. (1988). The empowerment process integrating theory and practice. The Academy of Management review: AMR, 13(3), 471-482.

Eylon \& Au. (1999). Exploring empowerment cross-cultural differences along the power distance dimension. International Journal of Intercultural Relations, 23(3), 373-385.

Fock H., Chiang F., Au-Yeung K., \& Hui M.K. (2011) The moderating effect of collectivistic orientation in psychological empowerment and job satisfaction relationship. International Journal of Hospitality Management, 30(2011), 319-328

Hui, M., Au, K., \& Fock H. (2004). Empowerment effects across cultures. Journal of International Business Studies, 35(1), 46-60.

Hirzel, A. H., Leyer, M., \& Moormann, J. (2017). The role of employee empowerment in the implementation of continuous improvement: Evidence from a case study of a financial services provider. International Journal of Operations \& Production Management, 37(10), 1563-1579.

Hoffman, R., \& Shipper, F. (2012). The impact of managerial skills on employee outcomes: A cross cultural study. The International Journal of Human Resource Management, 23(7), 1414-1435.

Hofstede, G. (1980). Culture's consequences: Comparing values, behaviors, institutions and organizations across nations. Beverly Hills, CA: Sage.

Hofstede, G., Neuijen, B., Ohayv, D., Daval, A., \& Sanders, G. (1990). Measuring organizational cultures: A qualitative and quantitative study across twenty cases. Administrative Science Quarterly, 2(35), 286-316.

Hofstede, G., Hofstede, G. J., \& Minkov, M. (2010). Culture and Organizations: Software of the Mind. New York: McGraw Hill.

Jang, S., Shen, W., Allen, T., \& Zhang, H. (2018). Societal individualism-collectivism and uncertainty avoidance as cultural moderators of relationships between job resources and strain. Journal of Organizational Behavior, 39(4), 507-524.

Kahn, W. (1990). Psychological conditions of personal engagement and disengagement at work. Academy of Management Journal, 33(4), 692-724.

Kanter, R. M. (1989). The new managerial work. Harvard Business Review, 66, 85.

Liden, R. C., \& Arad, S. (1996). A power perspective of empowerment and work groups: Implications for human resources management research. Research in Personnel and Human Resources Management, 14, 205-252.

Mathieu, J., Gilson, L., Ruddy, T., \& Zedeck, Sheldon. (2006). Empowerment and Team Effectiveness: An Empirical Test of an Integrated Model. Journal of Applied Psychology, 91(1), 97-108.

Maynard, M. T., Gilson, Lucy L., \& Mathieu, J. E. (2012). Empowerment—fad or fab? A multilevel review of the past two decades of research. Journal of Management, 38, 1231-1281.

Mclean, R.S., \& Antony, J. (2017). A conceptual continuous improvement implementation framework for UK manufacturing companies. Technical report, 34(7), 1015-1033. 
Mone, E., Eisinger, C., Guggenheim, K., Price, B., \& Stine, C. (2011). Performance management at the wheel: Driving employee engagement in organizations. Journal of Business and Psychology, 26(2), 205-212.

Prathiba, S. (2016). A Study on Impact of Employee Empowerment and Employee Engagement on Organisational Commitment. SIES Journal of Management, 12(2), 545-54.

Schaufeli, W.B., \& Bakker, A.B., 2004. Job demands, job resources, and their relationship with burnout and engagement: a multi-sample study. Journal of Organizational Behavior, 25(3), 293-315.

Schiele, H., \& Krummaker, S. (2011). Consortium benchmarking: Collaborative academic-practitioner case study research. Journal of Business Research, 64(10), 1137-1145.

Seibert, S., Silver, S. \& Randolph, W. (2004) Taking empowerment to the next level: a multiple-level model of empowerment, performance, and satisfaction. Academy of Management Journal, 47(3), 332-349

Shapiro, D. L, Kirkman, B.L., \& Courtney, H. G. (2007). Perceived causes and solutions of the translation problem in management research. Acad Manage J 2007, 50(2), 249-66.

Shuck, M. B., \& Wollard, K. (2010). Employee engagement \& HRD: A seminal review of the foundations. Human Resource Development Review, 9(1), 89-110.

Smith, J. (1996). Empowering people: how to bring out the best in your workforce. London: Kogan Page.

Spreitzer, G. M. (1995). Psychological empowerment in the workplace: Dimensions, measurement, and validation. Academy of Management Journal, 38, 1442-1465.

Thomas, K.W., \& Velthouse, B.A. (1990). Cognitive Elements of Empowerment: An "Interpretive" Model of Intrinsic Task Motivation. The Academy of Management Review, 15(4), 666-681.

Welch, M. (2011). The evolution of the employee engagement concept: Communication implications. Corporate Communications, 16(4), 328-346.

Willis Towers Watson. (2016). Retrieved from https://www.towerswatson.com/en-HK/Insights/ICTypes/Survey-Research-Results/2011/02/The-Power-of-Three--Taking-Engagement-to-NewHeights

Zhang \& Zhou. (2014). Empowering leadership, uncertainty avoidance, trust, and employee creativity: Interaction effects and a mediating mechanism. Organizational Behavior and Human Decision Processes, 124(2), 150-164. 